\title{
Fencing affects African wild dog movement patterns and population dynamics
}

\author{
Helen M. K. O’Neill, Sarah M. Durant \\ Stefanie Strebel and Rosie Woodroffe
}

\begin{abstract}
Wildlife fences are often considered an important tool in conservation. Fences are used in attempts to prevent human-wildlife conflict and reduce poaching, despite known negative impacts on landscape connectivity and animal movement patterns. Such impacts are likely to be particularly important for wide-ranging species, such as the African wild dog Lycaon pictus, which requires large areas of continuous habitat to fulfil its resource requirements. Laikipia County in northern Kenya is an important area for wild dogs but new wildlife fences are increasingly being built in this ecosystem. Using a long-term dataset from the area's free-ranging wild dog population, we evaluated the effect of wildlife fence structure on the ability of wild dogs to cross them. The extent to which fences impeded wild dog movement differed between fence designs, although individuals crossed fences of all types. Purposebuilt fence gaps increased passage through relatively impermeable fences. Nevertheless, low fence permeability can lead to packs, or parts of packs, becoming trapped on the wrong side of a fence, with consequences for population dynamics. Careful evaluation should be given to the necessity of erecting fences; ecological impact assessments should incorporate evaluation of impacts on animal movement patterns and should be undertaken for all large-scale fencing interventions. Where fencing is unavoidable, projects should use the most permeable fencing structures possible, both in the design of the fence and including as many purposebuilt gaps as possible, to minimize impacts on wide-ranging wildlife.
\end{abstract}

Keywords African wild dog, connectivity, fence, Lycaon pictus, movement ecology, wide-ranging

Supplementary material for this article is available at doi.org/10.1017/So030605320000320

Helen M. K. O’NeiLL $†$ (Corresponding author, (1) orcid.org/0000-0002-94584494), Sarah M. Durant and Rosie Woodroffe Institute of Zoology, Zoological Society of London, London, UK. E-mail h.o'neill@kent.ac.uk

Stefanie Strebel Department of Evolutionary Biology and Environmental Studies, University of Zurich, Zurich, Switzerland

*Also at: Centre for Biodiversity and Environment Research, Division of Biosciences, University College London, London, UK

$\dagger$ Current address: Durrell Institute of Conservation and Ecology, School of Anthropology and Conservation, University of Kent, Canterbury, UK

Received 19 September 2019. Revision requested 8 November 2019.

Accepted 16 April 2020. First published online 21 April 2021.

\section{Introduction}

T abitat fragmentation is a leading threat to global bio1 diversity (Millennium Ecosystem Assessment, 2005). As habitats become increasingly fragmented, wildlife populations also become fragmented in smaller, genetically isolated, subpopulations that will be at greater risk of extinction (Lande, 1988). This is of particular concern for wide-ranging species that are reliant on accessing large areas to fulfil their resource requirements, meaning that fragmentation can lead to such species being extirpated, even when habitat may remain (Løvschal et al., 2017). Fragmentation often increases the cost incurred by wildlife in obtaining vital resources and may even cut access off entirely (Epps et al., 2005; Løvschal et al., 2017). Fragmentation can occur as a result of habitat loss, but is also associated with the erection of barriers to movement such as fences (Clevenger \& Waltho, 2000).

Fences have been employed in attempts to mitigate numerous conservation issues, including human-wildlife conflict, invasive species control, prevention of disease transmission and delineation of protected area boundaries (Hayward \& Kerley, 2009; Gadd, 2012; Hayward \& Somers, 2012; Beale et al., 2013). In some cases fences have led to positive conservation outcomes such as reductions in human-elephant conflict (Knickerbocker \& Waithaka, 2005), protection of threatened native species from invasive species in New Zealand (Burns et al., 2012), or, in the case of the Critically Endangered hirola antelope Beatragus hunteri in Kenya, from native predators (Ali et al., 2018). However, although fences can have positive impacts, the effects are often mixed. Building and maintaining fences is costly, and the associated habitat fragmentation can require the use of expensive, complex conservation management strategies, including translocations, to maintain genetic diversity across metapopulations (Davies-Mostert et al., 2015; Buk et al., 2018). There are also reports of negative impacts, including mortalities, as a result of fencing preventing animals from accessing vital resources, and of individuals becoming entangled or being electrocuted by fences (Gadd, 2012; Pietersen et al., 2014). However, although there are multiple examples where fences have restricted the access of wild animals to vital resources (Gadd, 2012), thereby negatively affecting populations, the impact of such barriers on the movements of individual animals is poorly understood.

Some fencing projects have sought to minimize harmful effects by using fences with different levels of permeability, 
which block the passage of certain key species but allow other species to cross. Semi-permeable fence structures may be high enough for species to pass below, or low enough for species to jump over, but act as barriers to the movement of less agile species such as the elephant Loxodonta africana, the white rhinoceros Ceratotherium simum or the black rhinoceros Diceros bicornis. Similarly, purpose-built gaps, which permit the passage of some species but prevent the movement of others, are sometimes included in the structure of a fence to increase permeability (Dupuis-Désormeaux et al., 2016a). These gaps may allow animals to pass through the fence, but if there are few gaps then animals may have to move a considerable additional distance to use them. Fence gaps may also have impacts on the movement of wildlife species as they are likely to funnel them into certain areas (Little et al., 2002), thereby affecting species' distributions across a landscape (Dupuis-Desormeaux et al., 2016b).

The African wild dog Lycaon pictus is an extremely wide-ranging species (Woodroffe, 2010), categorized on the IUCN Red List as Endangered (Woodroffe \& SilleroZubiri, 2020). The species is threatened by habitat loss and fragmentation; it is estimated to have been extirpated from up to $93 \%$ of its former range (IUCN/SSC, 2007, 2012, 2015). Wild dogs need access to large, continuous areas of wildlifefriendly habitat to persist; increases in fencing would be expected to affect wild dogs negatively because they will fragment the landscape and confine packs to smaller areas. In South Africa, where wild dogs live in fenced reserves, the metapopulation has to be actively managed using translocations and reintroductions (Davies-Mostert et al., 2015), although some positive impacts of fencing have been found within this metapopulation as individuals have been shown to suffer lower mortality when released with an established social group into securely fenced reserves (Gusset et al., 2007, 2010). Wild dogs have also been recorded using fences to their advantage in catching larger prey, reducing their hunting effort (Davies-Mostert et al., 2013). However, as other large carnivores, including lions Panthera leo, often reach higher population densities within fenced reserves, wild dogs may be vulnerable to the negative impacts of increased interspecific competition, kleptoparasitism and predation (van Dyk \& Slotow, 2003; Darnell et al., 2014).

Here we explore the impacts of different fence designs on animal movements using data from a free-ranging population of African wild dogs in Laikipia, Kenya. We investigate whether fence structure affects wild dog movement patterns and crossing ability, whether purpose-built fence gaps are used by wild dogs to cross fences and if fence gaps affect their spatial distribution. Incidences of observed negative interactions between wild dog packs and fences are also presented, to provide context for the quantitative analyses.

\section{Study area}

The study area lies in Laikipia County in northern Kenya; a wooded savannah landscape (mean annual rainfall $590 \mathrm{~mm}$; Woodroffe, 2010). Laikipia supports the second highest density of large terrestrial mammalian wildlife in Kenya (Kinnaird \& O'Brien, 2012) and is an important area for many threatened species.

The landscape is divided into privately and community owned properties of $<1-386 \mathrm{~km}^{2}$, with land uses including traditional pastoralism, commercial livestock ranching, subsistence agriculture, large-scale farming, and tourism (Ulrich et al., 2012). The amount of wildlife fencing in Laikipia has increased since 2000. Many of the properties in Laikipia are fenced to demarcate their boundaries (Evans \& Adams, 2016; Yurco, 2017); fencing is also used in an attempt to reduce human-wildlife conflict and to reduce rhinoceros poaching by containing animals within protected reserves (DupuisDésormeaux et al., 2016a; Blair \& Meredith, 2017).

We focused on the effects of the fences of two of the largest wildlife properties in Laikipia, referred to here as Property A and Property B. These properties are used by wild dog packs (Supplementary Fig. 1) and employ three types of fencing (Fig. 1).

Property A comprises two sections. The property's ranching and tourism businesses are based in the western part (hereafter Property A1), which supports a wide variety of wildlife. Property $A_{1}\left(175 \mathrm{~km}^{2}\right)$ is fenced with a low-level, electrified Type A1 fence, which is raised from the ground (Fig. 1a). The fence is $55.9 \mathrm{~km}$ long and intended to restrict the movement of elephants and rhinoceroses. This fence has five purpose-built gaps (Fig. 1d, Supplementary Figs $2 \& 3$ ) that allow the passage of most wildlife species but prevent rhinoceroses moving off the property. The eastern part of Property A $\left(50 \mathrm{~km}^{2}\right.$; hereafter Property $\left.\mathrm{A}_{2}\right)$ is set aside for wildlife. It is separated from Property A 1 by a public road and is surrounded by a $31.9 \mathrm{~km}$ long Type $\mathrm{A}_{2}$ fence (Fig. 1b). This fence is also electrified but is intended as a barrier to medium and large bodied species. When first erected, the Type A2 fence had no gaps, but two gaps (Fig. 1d) have since been added.

Property B $\left(340 \mathrm{~km}^{2}\right)$ has a Type B fence (Fig. 1c) that is electrified and $141.6 \mathrm{~km}$ long. The fence was erected to try and reduce conflict with local communities by restricting the movement of all medium and large bodied mammals out of the property. It was erected in 2006 with three purpose-built gaps (Fig. 1d, Supplementary Figs 2 \& 3). These gaps are clustered in the north-west of the property, where it borders an area of wildlife-friendly habitat, away from human settlements. 

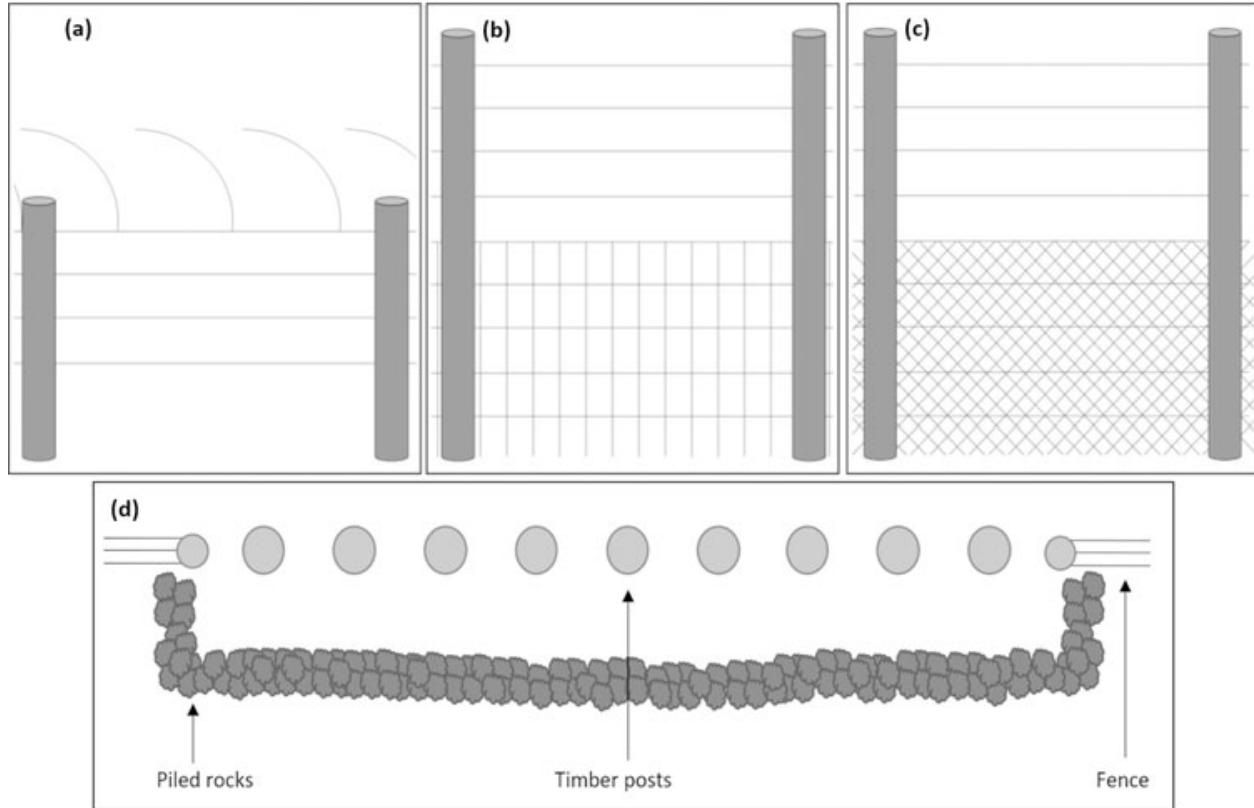

FIG. 1 The three fence structures used on two wildlife properties in Laikipia County, northern Kenya, referred to here as Property A and Property B: (a) Type Ai fence, which surrounds Property A1;

(b) Type A2 fence, which surrounds Property A2;

(c) Type B fence, which surrounds Property B; and

(d) design of the fence gaps.

\section{Methods}

\section{Wild dog data}

The wild dog population of Laikipia has been continually monitored since 2001; each study pack had at least one individual fitted with a VHF or GPS collar. Packs were visually observed at least once every 1-4 weeks. During observations, data were collected about pack size, behaviour and the reproductive and social status of pack members, providing a long-term demographic dataset (Woodroffe, 2010). The population's main prey species are Kirk's dikdik Madoqua kirkii and impala Aepyceros melampus, which are abundant throughout the study area (Woodroffe et al., 2007; Shorrocks et al., 2008).

We used data from GPS collars to investigate the effects of fencing on wild dog movement behaviour. Wild dogs were immobilized and collared as described by Woodroffe (2010). This study uses data collected during 2004-2017, when 27 wild dogs from 15 packs were fitted with GPS collars (GPS-Posrec, Televilt, TVP Positioning AB, Lindesberg, Sweden, and GPS-Plus, Vectronic Aerospace GmbH, Berlin, Germany). Of the GPS-collared wild dogs, 13 individuals from nine packs interacted with at least one of the fences surrounding Properties A and B.

GPS collars were programmed to record the wild dog's location 6-13 times per day. No pack had two individuals fitted with GPS collars concurrently. Wild dogs are highly crepuscular (Woodroffe et al., 2017), and so the collars were programmed to collect locations more frequently during dawn and dusk (Rabaiotti \& Woodroffe, 2019).

\section{The effect of fence structure on wild dog movement}

To analyse the effect of fence structure on fence crossing success by wild dogs, we compared the rate they crossed real fences with the rate they crossed simulated fence lines. Locations from the GPS collars were plotted and the number of times each wild dog successfully crossed a fence was counted. An individual was considered to have crossed a fence when a location was recorded on one side of a fence and the subsequent location was on the other side of the fence. Each record was checked to ensure it was a true crossing event and could not be a result of the individual circumnavigating the fence (Supplementary Fig. 4).

A step was defined as the movement between one location and the next; steps had both length (the straight-line distance in metres between consecutive locations) and duration (the difference in minutes between consecutive locations). The step lengths for each wild dog's movement pathway were calculated from the collar data. The number of steps that were close to a fence, and therefore could have resulted in a crossing, was also counted. Step durations varied with time of day, and between individuals, as the frequency of GPS data recording was not the same for all collars. The shortest step duration was 30-120 minutes. We calculated the mean step length for the shortest step duration for each wild dog; there was no correlation between the length of time and mean step length for that time period (Pearson's product-moment correlation: $t=0.80, \mathrm{df}=11$, $\mathrm{P}=0.44$ ). To define the areas close to the fences within which steps could have resulted in a crossing, we drew buffers around each fence for each wild dog; the buffer width was 
equal to that individual's mean step length at the shortest step duration (range: $0.42-2.02 \mathrm{~km}$; mean step length across all 13 individuals: $1.06 \mathrm{~km}$ ).

We created simulated fence lines in areas close to the real fences to generate a baseline fence crossing probability; i.e. the rate of crossing that would be expected if a fence did not present a movement barrier. By randomly creating two points at least $10 \mathrm{~km}$ apart and joining them with a straight line, fences were simulated that were randomly orientated in areas close to the real fences (within $10 \mathrm{~km}$ ) but where no fences, or other potential movement barriers (e.g. major roads and rivers), actually existed. We followed the same process as described above for the real fences to establish a baseline measurement of crossing success. These data were analysed using a generalized linear mixed model (GLMM) with binomial distribution. Fence crossing success as a binary response variable (crossed successfully vs failed to cross) was compared for fence type ( $A_{1}, A_{2}$ or $B$ ), with individual wild dog identity as a random variable.

\section{Use of purpose-built fence gaps by wild dogs}

To determine whether wild dogs used fence gaps to cross fences, we estimated the proportion of successful crossings that occurred in the vicinity of the gaps. Steps that crossed the fence and had at least part of their length within $1 \mathrm{~km}$ of a fence gap location (hereafter referred to as the fence gap buffer) were assumed to have made use of the gap. A buffer distance of $1 \mathrm{~km}$ was chosen as it approximated the mean step length of $1.06 \mathrm{~km}$ for the 13 GPS-collared wild dogs. The number of crossings in the fence gap buffer was then compared with the expected number of crossings using a $\chi^{2}$ test. For each fence type, a $2 \times 1$ contingency table was used with the expected number of crossings calculated as the total number of fence crossings multiplied by the proportion of the fence that fell within the fence gap buffer.

For properties where wild dogs preferentially used fence gaps to cross fences, we investigated the impact of the fence gaps on the spatial distribution of wild dog locations. To capture the effects of the gaps on the wild dogs' distribution beyond their immediate passage though the gaps, a $10 \mathrm{~km}$ wide buffer was created around the property's fence line and wild dog locations within this buffer used for the analysis. Data from denning wild dog packs were not included in the analysis because during denning movement patterns are restricted to areas close to the den. Using only locations recorded at $13.00\left(n=304\right.$ from 3 individuals: $W_{D F} 30$, WDM118 and WDM97), when the wild dogs were likely to be resting (Woodroffe et al., 2017) and therefore not in the process of travelling through the fence gaps, the distance from each location to the nearest gap was calculated. An equal number $(n=304)$ of random points was generated within the $10 \mathrm{~km}$ buffer for comparison, and the distance from each of these random points to the nearest gap was also calculated. The distances between the wild dog locations and the fence gaps were compared with those of the random points using a Welch two sample $t$ test.

\section{Direct observations of interactions between wild dogs and fences}

To provide insight into the impacts of fences on wild dog packs, we collated incidents of observed interactions between wild dogs and fences in Laikipia in which packs' movement or dynamics were clearly affected by fences.

\section{Roadkill}

Vehicle collisions can be an important cause of mortality for wild dogs (van der Meer et al., 2014). Information on cause of death has been collected for all dead wild dogs (collared and uncollared) found in Laikipia since project inception in 2001. We used data collected on roadkilled individuals to evaluate whether there may be higher rates of roadkill on roads close to fences.

\section{Results}

\section{The effect of fence structure on wild dog movement}

The per cent of wild dog steps close to a fence that resulted in fence crossings varied significantly with fence type. For the simulated fences, $17.8 \%$ of steps within the buffer distance resulted in a crossing. The crossing frequency of the Type A1 fence was $18.0 \%$ and was not significantly different from that of the simulated fences (Table 1, Supplementary Table 1). The Type A2 fence had a crossing success of $13.7 \%$, significantly lower than for the simulated fences (Table 1, Supplementary Table 1). The Type B fence presented the greatest movement barrier: only $2.9 \%$ of the steps within the buffer resulted in a crossing (Table 1, Supplementary Table 1).

\section{Use of purpose-built fence gaps by wild dogs}

Successful crossings of the Type A1 and A2 fences by collared wild dogs did not have part of their length within $1,000 \mathrm{~m}$ of a purpose-built fence gap more often than would be expected by chance (Table 2). The majority of the successful crossings of Property B's fence (61.5\%) had part of their length within the fence gap buffers $(\mathrm{P}<0.001$; Table 2). As only the Type B fence had a significantly greater than expected number of crossings close to fence gaps, the effect of fence gaps on wild dog distribution was only investigated in relation to this fence. Wild dog resting locations were found to be closer to the gaps than would otherwise 
TABLE 1 GLMM of the effect of fence structure (Fig. 1) on fence crossing success by African wild dogs Lycaon pictus. The model included individual ID as a random effect, which was not significant.

\begin{tabular}{lcc}
\hline Fence type & Coefficient \pm SE & \multicolumn{1}{c}{$\mathrm{P}$} \\
\hline A1 vs simulated & $0.059 \pm 0.09$ & 0.52 \\
A2 vs simulated & $-0.36 \pm 0.12$ & 0.003 \\
B vs simulated & $-2.10 \pm 0.17$ & $<0.001$ \\
\hline
\end{tabular}

TABLE 2 Use of purpose-built fence gaps by wild dogs. The expected number of crossings was calculated as the total number of fence crossings multiplied by the proportion of the fence line within the fence gap buffer.

\begin{tabular}{|c|c|c|c|c|c|}
\hline \multirow[b]{2}{*}{ Property } & \multirow{2}{*}{$\begin{array}{l}\text { Total no. of } \\
\text { successful } \\
\text { fence } \\
\text { crossings }\end{array}$} & \multicolumn{2}{|c|}{$\begin{array}{l}\text { No. of crossings } \\
<1,000 \mathrm{~m} \text { from } \\
\text { fence gap }\end{array}$} & \multirow[b]{2}{*}{$\chi^{2}$} & \multirow[b]{2}{*}{$\mathrm{P}$} \\
\hline & & Observed & Expected & & \\
\hline$\overline{\mathrm{A} 1}$ & 411 & 85 & 67.22 & 2.08 & 0.15 \\
\hline $\mathrm{A} 2$ & 175 & 26 & 22.21 & 0.34 & 0.56 \\
\hline $\mathrm{B}$ & 52 & 32 & 2.20 & 25.96 & $<0.001$ \\
\hline
\end{tabular}

be expected. Locations randomly generated within the $10 \mathrm{~km}$ fence buffer were on average $16.66 \mathrm{~km}$ from the fence gaps. Wild dog locations were an average distance of $13.52 \mathrm{~km}$ from the fence gaps (number of wild $\operatorname{dogs}=3 ; t=-5.07$, $\mathrm{P}<0.001$ )

\section{Direct observations of interactions between wild dogs and fences}

Although interactions with fences are rarely observed, there have been at least 19 incidents since 2001 that have had tangible impacts on wild dog movement and pack dynamics. The recorded encounters observed between wild dogs and fences within the study area are summarized in Table 3.

Dispersal group split Two VHF-collared wild dogs from the same natal pack dispersed from their pack's territory in the north of Laikipia. The wild dogs travelled south and separated while close to the Property B fence. One of the collared dogs entered Property B, and the other continued south. It is unusual for single sex dispersal groups to separate. Since 2001, 38 natal dispersals have been recorded involving collared wild dogs (Woodroffe et al., 2019b); only two groups are known to have separated during dispersal, both in association with fences.

Pack separation A resident pack made an excursion beyond the eastern bounds of their normal territory and were subsequently seen separated by a wildlife fence. VHF tracking and sighting reports of the pack continued over
TABLE 3 Number of occurrences of five impacts of fences observed during the course of this study.

\begin{tabular}{lcl}
\hline Incident type & $\begin{array}{l}\text { No. of } \\
\text { occurrences }\end{array}$ & Fences involved \\
\hline $\begin{array}{l}\text { Dispersal group split } \\
\text { Permanent pack }\end{array}$ & 2 & $\begin{array}{l}\text { Property B } \\
\text { separation }\end{array}$ \\
Roadkill & 2 & $\begin{array}{l}\text { Property } \\
\text { Livestock depredation }\end{array}$ \\
Pack extinction & 4 & Property A2 \\
& 10 & Property B \\
\end{tabular}

the next 4 months, although the number of individuals seen declined from the original 20 to 8 . Two animals, including the alpha female, eventually returned to the pack's core territory but a small group, believed to be all male and including the alpha male, remained trapped inside the fence.

Livestock depredation A pack of wild dogs (hereafter $\mathrm{PB}$ pack) whose territory was centred on Property B became separated by the fence, with four individuals inside the fence on Property B, and 13 individuals outside, on neighbouring community land. It is likely that the 13 individuals had used one of the purpose-built gaps to cross the fence and had then moved away from the gaps and were unable to find their way back. During the time the pack was separated there were several reports of depredation of sheep and goats by the wild dogs outside the property and the pack was threatened with being poisoned. After several weeks, staff from Property B were able to cut part of the fence, to reunite the pack, after which there were no more depredation reports.

Pack extinction The PB pack was seen near the Property B fence soon after the death of the pack's alpha female. The alpha male was calling and looking at a lone, unrelated young female from a nearby pack, who was on the other side of the fence, calling and looking towards the PB pack but unable to reach them (Supplementary Plate 1). The PB pack had no female members unrelated to the alpha male that could take the place of the deceased alpha female. Packs in this situation often leave their territories in search of new females, and may split up (Woodroffe et al., 2019a). Soon after this encounter, the PB pack left Property B and moved into community areas where there were several reports of livestock depredation. The alpha male died during this time; the rest of the pack split and were lost to monitoring. After the encounter the young female returned to her pack, and soon afterwards the alpha male of this pack was killed in retaliation for the pack's livestock depredation. It is not known what happened to the rest of the pack, including the young female, but it is likely they were also killed. 


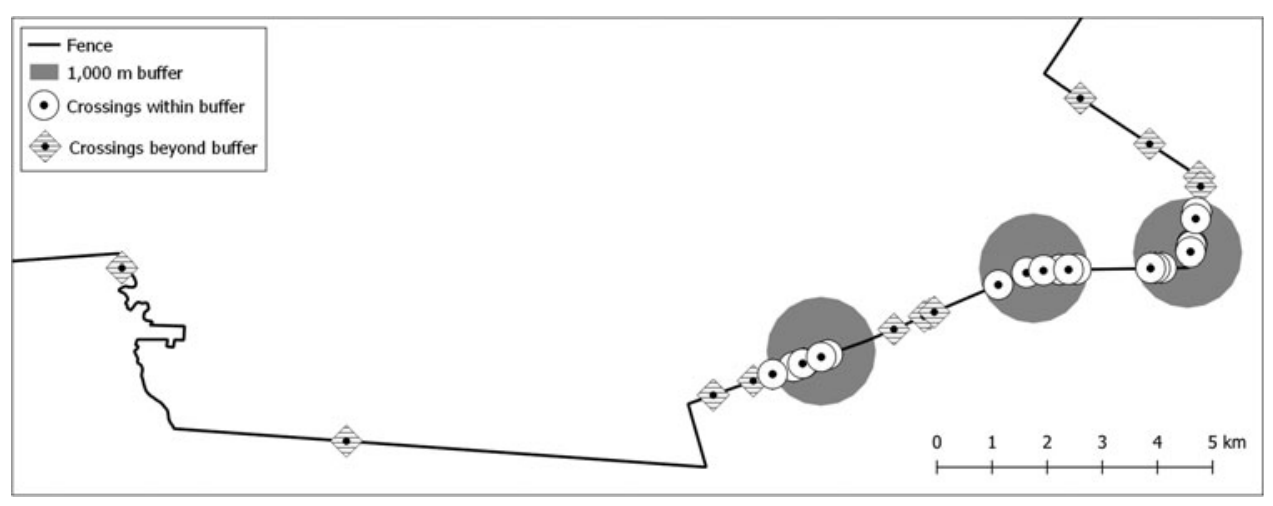

FIG. 2 Part of the Property B fence showing the $1,000 \mathrm{~m}$ buffer around three fence gaps, and where tracks of GPScollared wild dogs Lycaon pictus crossed the fence within and beyond these buffers.

\section{Roadkill}

Since 2001, 11 wild dogs have been recorded killed on the roads in Laikipia, four of which $(36.4 \%)$ were on the stretch of road next to the Type A2 fence. Laikipia has c. $542.7 \mathrm{~km}$ of main roads; the stretch of road next to the Type $\mathrm{A}_{2}$ fence is c. $13.6 \mathrm{~km}$ in length $(2.5 \%)$.

\section{Discussion}

Our findings suggest that fences can affect wild dog movement and population dynamics. Based on the wild dog movement patterns observed, the fences in this study appeared to be broadly successful in their designs. The aim of the Type A1 fence is to restrict movement of megaherbivores but not smaller species, and our analyses found no evidence that the fence affected wild dog movement or population dynamics. The aim of the Type $\mathrm{A}_{2}$ fence is to restrict the movements of medium and large bodied species: although wild dogs crossed the fence at a reduced rate, they were still able to cross, although there was no evidence they used the fence gaps. The Type B fence is intended to restrict the movements of medium and large bodied species: wild dogs had significantly lower numbers of successful crossings than would be expected if the fence was completely permeable; the analysis also suggested that wild dogs were reliant on using purpose-built gaps to cross this fence. The purpose-built gaps in the Type B fence had a significant effect on wild dog spatial distribution, with daytime resting locations clustered close to the gaps; suggesting the gaps are at least partly successful at channelling animals into certain areas. Although the fences were, overall, largely successful at achieving their intended impacts, there have nonetheless been numerous negative impacts on the wild dog population observed as a result of the barrier effects of these fences, and others in Laikipia, including permanent social group separations, livestock depredation, retaliatory killings and roadkill.

These results show that some fences within the study area have had important effects on one of the threatened species living there; however, in addition to structure playing an important role, maintenance is also likely to be important. The
Type A2 fence had higher permeability than the Type B fence despite the similarity in their structures; this may reflect this fence's state of repair. Fences are expensive and difficult to maintain (Hayward \& Kerley, 2009); this fence is substantially older than the fence around Property B and holes have been observed, which are likely to be used by animals, such as wild dogs, to traverse the fence. This higher level of overall permeability also probably explains the relatively low levels of fence gap use observed for this fence. Despite its relative permeability, the Type A2 fence may have had demographic consequences for the wild dog population, as several wild dogs have been killed by vehicle collisions on the road that runs along one side of the fence (Table 3). It is not possible to discern whether these fatalities were a direct result of the fence, as wild dogs are susceptible to being killed on roads regardless of the presence of fences (Woodroffe \& Ginsberg, 1999). However, we have observed individuals from another threatened species, the cheetah Acinonyx jubatus, being chased along this road by people in vehicles whilst attempting to cross the fence between the road and Property A2.

The movement behaviour and crossing ability of wild dogs suggest that the design of fence structures and/or the inclusion of fence gaps are vital for maintaining landscape connectivity. Fence A1 had no detectable impact on the ability of wild dogs to cross, whereas the Type B fence was relatively impermeable, with most crossings probably involving the use of fence gaps. Our analysis used a buffer distance of $1 \mathrm{~km}$ around the fence gaps, assuming all crossings within this distance used them, although it is possible that some crossings within the buffer did not use the gaps, and some outside the buffer did use the gaps. Most of the crossings of the Type B fence were clustered around the fence gaps (Fig. 2), although not all were within the buffer distance, suggesting that the use of the gaps could be greater. The importance of the fence gaps is also indicated by the wild dogs' GPS collar locations being significantly closer to the gaps than would be expected by chance, suggesting that gaps channel wild dogs into specific areas.

As fence gaps appear to channel wild dog movement and affect spatial distribution, careful consideration should be 
given to both their location and the number incorporated into a fence. An aim of the fence around Property B is to prevent medium and large bodied wildlife from moving onto community land, to try to reduce conflict with local communities; the fence gaps are in areas of wildlife-friendly habitat, away from human settlements and agriculture. The gaps appear successful in channelling movement of species into certain areas, away from local communities, as the wild dogs tended to stay in areas close to the gaps. However, because the gaps are close to each other (Fig. 2) there are long stretches of the fence that are almost completely impermeable. This has inadvertently caused problems when individuals or packs have left the property, then moved away from the gaps and have been unable to return.

The African wild $\operatorname{dog}$ is an obligate social species. Resident packs have a strong group bond, and therefore when packs are separated by a fence the two groups will usually remain close to each other over many days rather than splitting immediately. When this happened with the $\mathrm{PB}$ pack, the result was that the individuals on the outside of the fence were left in an area with little wild prey, where they were reported attacking livestock. Instances of wild dogs being effectively stuck on the apparent wrong side of a fence may therefore have led to human-wild dog conflict, have been associated with the death of individual wild dogs, and contributed to the loss of entire packs. It is important to consider what to do when animals become trapped on the wrong side of a fence. There is a contradiction between erecting a barrier to separate wildlife from local communities and then building a hole into it. Planning appropriate management strategies is important because, as we found, intervention may be required when animals have crossed to the wrong side of a fence and are unable to return (Krebs et al., 2001; Sinclair, 2008).

Fences are widely recognized as causing landscape fragmentation and reducing connectivity, and have contributed to the loss of large terrestrial mammal migrations (Harris et al., 2009). This has prompted the Convention on Migratory Species to develop guidelines to address the impact of fences and other linear movement barriers on migratory species (Wingard et al., 2014). The evidence from our study suggests it may be possible to design fences that restrict the movement of certain groups of species, without reducing landscape connectivity for others. However, although these fences do not appear to measurably affect connectivity for wild dogs, and thus probably also other similarly sized species, they are likely to affect other non-target species. Although intended primarily to prevent rhinoceros movement and channel elephant movement, these fences probably also affect the movements of other, non-target, megaherbivores such as the giraffe Giraffa camelopardalis, as they are not able to cross the fence freely and therefore must also use the purpose-built gaps to move on and off the properties. Thus although these fences may have had a positive impact on elephant and rhinoceros conservation, the increased costs to other threatened but non-target species also need to be evaluated.

The methodologies used here could be used more widely to assess permeability of fence types for a range of species, as well as the extent to which purpose-built gaps and other mitigation methods are successful. As fences have been identified as a key cause of the loss of large-scale migrations (Harris et al., 2009), these methodologies could be used to evaluate the level of impact that fences are having on the movements of animals and help identify the mitigation methods required. This information could be used in environmental impact assessments, which should be conducted before fences are erected, and could also be used after construction to evaluate impacts and inform future modifications.

Our findings show that relatively impermeable fences can have effects on long-term connectivity levels across a landscape for wide-ranging species, with short-term impacts on the population. Where fencing is considered essential, preference should be given to the building of more permeable fences. Where less permeable fencing is considered necessary, careful consideration should be given to planning how to react if animals (including parts of social groups) become stranded on the wrong side of the fence, so that rapid mitigation is possible, as well as to the techniques for mitigating long-term habitat fragmentation and connectivity loss.

Acknowledgements We thank the landowners and communities within our study site for hosting our research, Kenya Wildlife Service for collaboration, and the Kenya National Council for Science and Technology (permit NACOSTI/P/14/9920/1659) for research permission, and funders and research assistants too numerous to list individually.

Author contributions Study design: HMKON, SMD, RW; collection of field data: RW, HMKON, SS; long-term field data: RW; analyses, writing: HMKON; editing: RW, SMD, SS.

\section{Conflicts of interest None.}

Ethical standards Wild dogs were captured and handled as described by Woodroffe (2011) in collaboration with the Kenya Wildlife Service, with permission from the Kenyan Ministry of Science and Technology, according to guidelines of the IUCN/ Species Survival Commission Canid Specialist Group and in conformity with the guidelines of the American Society of Mammalogists (Gannon et al., 2007), following a protocol approved by the Ethics Committee of the Zoological Society of London. This work abided by the Oryx guidelines on ethical standards.

\section{References}

Ali, A.H., Kauffman, M.J., Amin, R., Kibara, A., King, J., Mallon, D. et al. (2018) Demographic drivers of a refugee species: large-scale experiments guide strategies for reintroductions of hirola. Ecological Applications, 28, 275-283. 
Beale, C.M., Rensberg, S. van Bond, W.J., Coughenour, M., Fynn, R., GAYlard, A. et al. (2013) Ten lessons for the conservation of African savannah ecosystems. Biological Conservation, 167, 224-232.

Blair, A.G. \& Meredith, T.C. (2017) Community perception of the real impacts of human-wildlife conflict in Laikipia, Kenya: capturing the relative significance of high-frequency, low-severity events. Oryx, 52, 497-507.

Buk, K.G., van der Merwe, V.C., Marnewick, K. \& Funston, P.J. (2018) Conservation of severely fragmented populations: lessons from the transformation of uncoordinated reintroductions of cheetahs (Acinonyx jubatus) into a managed metapopulation with self-sustained growth. Biodiversity and Conservation, 27, 3393-3423.

Burns, B., Innes, J. \& Day, T. (2012) The use and potential of pest-proof fencing for ecosystem restoration and fauna conservation in New Zealand. In Fencing for Conservation (eds M.J. Somers \& M. Hayward), pp. 65-90. Springer New York, New York, USA.

Clevenger, A.P. \& Waltho, N. (2000) Factors influencing the effectiveness of wildlife underpasses in Banff National Park, Alberta, Canada. Conservation Biology, 14, 47-56.

Darnell, A.M., Graf, J.A., Somers, M.J., Slotow, R. \& Szykman Gunther, M. (2014) Space use of African wild dogs in relation to other large carnivores. PLOS ONE, 9, e98846.

Davies-Mostert, H.T., Mills, M.G.L. \& Macdonald, D.W. (2013) Hard boundaries influence African wild dogs' diet and prey selection. Journal of Applied Ecology, 50, 1358-1366.

Davies-Mostert, H.T., Mills, M.G.L. \& Macdonald, D.W. (2015) The demography and dynamics of an expanding, managed African wild dog metapopulation. African Journal of Wildlife Research, $45,258-273$.

Dupuis-Désormeaux, M., Davidson, Z., Mwololo, M., Kisio, E. \& MacDonald, S.E. (2016a) Usage of specialized fence-gaps in a black rhinoceros conservancy in Kenya. African Journal of Wildlife Research, 46, 22-32.

Dupuis-Desormeaux, M., Davidson, Z., Pratt, L., Mwololo, M. \& MacDonald, S.E. (2016b) Testing the effects of perimeter fencing and elephant exclosures on lion predation patterns in a Kenyan wildlife conservancy. PeerJ, 4, e1681.

Epps, C.W., Palsbøll, P.J., Wehausen, J.D., Roderick, G.K., Ramey, R.R. \& McCullough, D.R. (2005) Highways block gene flow and cause a rapid decline in genetic diversity of desert bighorn sheep. Ecology Letters, 8, 1029-1038.

Evans, L.A. \& Adams, W.M. (2016) Fencing elephants: the hidden politics of wildlife fencing in Laikipia, Kenya. Land Use Policy, $51,215-228$.

GADD, M.E. (2012) Barriers, the beef industry and unnatural selection: A review of the impact of veterinary fencing on mammals in Southern Africa. In Fencing for Conservation (eds M.J. Somers \& M. Hayward), pp. 153-186. Springer New York, New York, USA.

Gannon, W.L., Sikes, R.S. \& The Animal Care and Use Committee of The American Society of Mammalogists (2007) Guidelines of the American Society of Mammalogists for the use of wild mammals in research. Journal of Mammalogy, $88,809-823$

Gusset, M., Ryan, S.J., Hofmeyr, M., van Dyk, G., DaviesMostert, H.T., Graf, J.A. et al. (2007) Efforts going to the dogs? Evaluating attempts to re-introduce endangered wild dogs in South Africa: re-introduction success in wild dogs. Journal of Applied Ecology, 45, 100-108.

Gusset, M., Stewart, G.B., Bowler, D.E. \& Pullin, A.S. (2010) Wild dog reintroductions in South Africa: a systematic review and cross-validation of an endangered species recovery programme. Journal for Nature Conservation, 18, 230-234.
Harris, G., Thirgood, S., Hopcraft, J., Cromsight, J. \& Berger, J. (2009) Global decline in aggregated migrations of large terrestrial mammals. Endangered Species Research, 7, 55-76.

Hayward, M.W. \& Kerley, G.I.H. (2009) Fencing for conservation: restriction of evolutionary potential or a riposte to threatening processes? Biological Conservation, 142, 1-13.

Hayward, M.W. \& Somers, M.J. (2012) An introduction to fencing for conservation. In Fencing for Conservation (eds M.J. Somers \& M. Hayward), pp. 1-6. Springer New York, New York, USA.

IUCN/SSC (2007) Regional Conservation Strategy for the Cheetah and African Wild Dog in Eastern Africa. IUCN Species Survival Commission, Gland, Switzerland.

IUCN/SSC (2012) Regional Conservation Strategy for the Cheetah and African Wild Dog in Western, Central and Northern Africa. IUCN Species Survival Commission, Gland, Switzerland.

IUCN/SSC (2015) Review of the Regional Conservation Strategy for the Cheetah and African Wild Dog in Southern Africa. IUCN Species Survival Commission, Gland, Switzerland.

Kinnaird, M.F. \& O'Brien, T.G. (2012) Effects of private-land use, livestock management, and human tolerance on diversity, distribution, and abundance of large African mammals: livestock and large mammals in Kenya. Conservation Biology, 26, 1026-1039.

Knickerbocker, T.J. \& Waithaka, J. (2005) People and elephants in the Shimba Hills, Kenya. Conservation Biology Series Cambridge, 9, 224.

Krebs, C.J., Boutin, S. \& Boonstra, R. (eds) (2001) Ecosystem Dynamics of the Boreal Forest: The Kluane Project. Oxford University Press, Oxford, UK.

LANDE, R. (1988) Genetics and demography in biological conservation. Science, 241, 1455-1460.

Little, S.J., Harcourt, R.G. \& Clevenger, A.P. (2002) Do wildlife passages act as prey-traps? Biological Conservation, 107, 135-145.

Løvschal, M., Bøcher, P.K., Pilgaard, J., Amoke, I., Odingo, A., Thuo, A. \& Svenning, J.-C. (2017) Fencing bodes a rapid collapse of the unique Greater Mara ecosystem. Scientific Reports, 7, 41450.

Millennium Ecosystem Assessment (2005) Ecosystems and Human Well-Being: Biodiversity Synthesis. World Resources Institute, Washington, DC, USA.

Pietersen, D.W., McKechnie, A.E. \& Jansen, R. (2014) A review of the anthropogenic threats faced by Temminck's ground pangolin, Smutsia temminckii, in Southern Africa. South African Journal of Wildlife Research, 44, 167-178.

Rabaiotti, D. \& Woodroffe, R. (2019) Coping with climate change: limited behavioral responses to hot weather in a tropical carnivore. Oecologia, 189, 587-599.

Shorrocks, B., Cristescu, B. \& Magane, S. (2008) Estimating density of Kirk's dik-dik (Madoqua kirkii Günther), impala (Aepyceros melampus Lichtenstein) and common zebra (Equus burchelli Gray) at Mpala, Laikipia District, Kenya. African Journal of Ecology, 46, 612-619.

SinClAir, A. (2008) Integrating conservation in human and natural ecosystem. In Serengeti III: Human Impacts on Ecosystem Dynamics (eds C. Packer, J.M. Fryxell, A.R.E. Sinclair \& S.A.R. Mduma), pp. 471-495. The University of Chicago Press, Chicago, USA.

Ulrich, A., Speranza, C.I., Roden, P., Kiteme, B., Wiesmann, U. \& NÜsser, M. (2012) Small-scale farming in semi-arid areas: livelihood dynamics between 1997 and 2010 in Laikipia, Kenya. Journal of Rural Studies, 28, 241-251.

van der Meer, E., Fritz, H., Blinston, P. \& Rasmussen, G.S.A. (2014) Ecological trap in the buffer zone of a protected area: effects of indirect anthropogenic mortality on the African wild dog Lycaon pictus. Oryx, 48, 285-293. 
VAN Dyk, G. \& Slotow, R. (2003) The effects of fences and lions on the ecology of African wild dogs reintroduced to Pilanesberg National Park, South Africa. African Zoology, 38, 79-94.

Wingard, J., Zahler, P., Victurine, R., Bayasgalan, O. \& BuUveibaAtaR, B. (2014) Guidelines for Addressing the Impact of Linear Infrastructure on Large Migratory Mammals in Central Asia. United Nations Environment Programme (UNEP)/Convention on the Conservation of Migratory Species of Wild Animals (CMS) Secretariat, Bonn, Germany.

Woodroffe, R. (2010) Ranging behaviour of African wild dog packs in a human-dominated landscape. Journal of Zoology, 283, 88-97.

Woodroffe, R. (2011) Demography of a recovering African wild dog (Lycaon pictus) population. Journal of Mammalogy, 92, 305-315.

Woodroffe, R. \& Ginsberg, J.R. (1999) Conserving the African wild dog Lycaon pictus. I. Diagnosing and treating causes of decline. Oryx, 33, 132-142.

Woodroffe, R., Lindsey, P.A., Romañach, S.S. \& ole Ranah, S.M.K. (2007) African wild dogs (Lycaon pictus) can subsist on small prey: implications for conservation. Journal of Mammalogy, $88,181-193$.

Woodroffe, R., Groom, R. \& McNutt, J.W. (2017) Hot dogs: high ambient temperatures impact reproductive success in a tropical carnivore. Journal of Animal Ecology, 86, 1329-1338.

Woodroffe, R., O’Neill, H. \& Rabaiotti, D. (2019a) Within- and between-group dynamics in an obligate cooperative breeder. Journal of Animal Ecology, 89, 530-540.

Woodroffe, R., Rabaiotti, D., NGatia, D.K., Smallwood, T.R.C., Strebel, S. \& O'Neill, H.M.K. (2019b) Dispersal behaviour of African wild dogs in Kenya. African Journal of Ecology, 58, 46-57. Woodroffe, R. \& Sillero-Zubiri, C. (2020) Lycaon pictus (amended version of 2012 assessment). In The IUCN Red List of Threatened Species 2020: e.T12436A166502262. dx.doi.org/10.2305/ IUCN.UK.2020-1.RLTS.T12436A166502262.en [accessed 20 August 2020].

YURCO, K. (2017) Herders and herdsmen: the remaking of pastoral livelihoods in Laikipia, Kenya. Pastoralism, 7, 15. 